ones, would acquire superior authority without justifiable motives. Dr. Auwers, who is undoubtedly the most competent person in such matters at the present time, has well delineated the limits of his fundamental catalogue, calling it not purely and simply fundamental, but "fundamental for the observations of the zones of the Astronomische Gesellschaft." In other words, he has not intended to do anything else than furnish an indispensable basis for the great international undertaking about the zones, and has set up a guard against extending the signification of "fundamental" that should legitimise every delicate use of his stellar positions. The researches to which he is attending now, and to which the Paris Conference justly attributes "un intérêt scientifique de premier ordre," prove how in his mind (as in those of all the astronomers assembled in Paris) the fundamental catalogue now in use may be considered alike provisional, just as the new catalogue to be compiled at the end of this century for the needs of national ephemerides. To give to day the title and the authority of a fundamental catalogue to a collection of stars is not sufficient in fact for the single stars to answer simply to the conditions which are enumerated at page 6 (Appendix C) of the Anntuaire du Bureau des Longitudes for I897; it is necessary that their positions be founded on absolute observations, cx. ecuted with all the precision of which perfected modern instruments are susceptible, and on an exhaustive discussion of the series obtained till now on the same stars at Greenwich, Pulkova, Leyden, Washington, and in a few other observatories. For the present time the needs of the practice will be satisfied with collections like those of Auwers, Boss, Safford, and similar astronomers.

After all, if an international accordance were proposed ex. clusively to cause the four great ephemerides to adopt a uniform system of constants and of fundamental stars (as it appcars to have been decided at Paris), without taking care at the same time that the reasons for the preference granted to such a system should consist in the undeniable superiority of it with regard to every other pre-existing, one might say that the agreement shows the absurdity of losing time, labour and money in the compilation of four different ephemerides, whilst one alone is enough for the needs of astronomy and navigation. In fact, for what object are four separate bodies of calculators employed to draw from planetary tables the places of the sun, moon and other bodies of our system? Would not one office alone, even international, be more than enough, and one sole almanac, published in several languages? And would it not be convenient to profit by the occasion to separate more clearly than has hitherto been done what is necessary for astronomers from that which is sufficient for geodetical observers, for geographers, for sailors? The papers in the Astronomical foumal touch this matter with great ability, calling attention to the fact that the national ephemerides (except, perhaps, that of Berlin) show rather too much the effects of their practical destination; if this could be fused with the supreme scope of astronomy some centuries ago, when the decay of astrological tendencies obliged science, from reasons of self-preservation, to find for herself a utilitarian basis, it is not at the end of the nineteenth century that she should found on its applications the justification of her existence. Like geometry, like all positive and speculative knowledge, like fine art, even the science of the stars aims especially at the honour of the human mind, and, from this point of view, the discovery of Neptune is worth as much as the discovery of a new salutary remedy or of a new electrical engine. On the other hand, the positions of the stars and planets are now known and calculated with a precision far superior to that which suffice for the applications. An immediate accord like that of Paris seems thus superfluous for applied astronomy and premature for pure astronomy. In any way, I agree with Messrs. Boss and Chandler in the view that if an agreement is to be come to, it is not in the form in which it was given at Paris. American astronomers justly note that the bureaucratic governmental character of the four offices publish. ing the ephemerides is not a sufficient title for them to represent all official and private astronomical science of the different countries in the definition of a merely scientific controversy of such moment. The directors of the four ephemerides indisputably occupy an eminent position amongst their colleagues; but, whatever may be their personal merits, their opinion (in a matter that touches the foundations of science) is not such as to impress itself authoritatively and without discussion.

Moreover, I allow myself to add that such an opinion cannot bind that of the numerous astronomers that belong to countries where ephemerides are not published, and where they are compiled (as at Trieste and at San Fernando) second-hand. The resolution adopted by the organisers of the Conference of inviting Messrs. Gill and Backlund, with a deliberative vote, Messrs. Van de Sande Bakhurzen and Trépied with a consultative rote, does not seem to me to represent anything more than a well-deserved homage rendered to those learned astronomers, and perhaps might contribute to render more significant the exclusion of other countries, such as Austria-Hungary, Italy, Sweden, Norway, Denmark, the Argentine Republic, whose astronomers till now have strongly and efficaciously contributed to the theoretical and practical study of the arguments. As to what refers specially to my own country, it may not be inopportune to recall to mind the ancient series of ephemerides published, first at Bologna, afterwards at Milan, which was interrupted twenty - five years ago in order not to lose time and money by repeating what was abundantly done at Paris, Berlin, London and Washington. The history of the Milan Observatory in this last quarter of the century, proves that the promises made by its director Schiaparelli were not vain, that thus the Observatory might "dedicate itsclf with greater alacrity to those researches that constitute the real progress of science" (consacrarsicon maggiore alacritiz a quelle ricerche, che costituiscono il z'ero progresso nelle scienze).

Finally, I believe that the discussion on the conclusions and aims of the Paris Conference should be continued by correspondence in scientific periodicals, as well as by direct treaty between the more competent bodies. And, perhaps, it would not be without some utility were the Royal Astronomical Society and the Astronomische Gesellschaft to iagree to examine and extend the plan devised some few years since by Dr. Gill for an international Congress of Astronomers, by which alone the deliberations of the Conference could have full and authoritative sanction.

Fr. PORRO

P.S.-The present paper was already finished when I read, in No. 413 of the Astronomical Tournal, Prof. Newcomb's reply to the criticism of Prof. Boss. Notwithstanding the reasons strenuously advanced by the learned astronomer of Washington in support of his proposal of a new value for precession, it does not seem doubtful that the question must be considered from a wider and more general point of view. No one contests the delicacy and the rigour of the procedure adopted by Newcomb in drawing out his precession: no one denies but that he has treated the difficult argument in a masterly manner, enlightening it with his original and profound views. Where it seems to me that Boss dissents from Newcomb is in the opportunity of expend. ing such talent and labour about a material already exhausted and not susceptible of giving more sure results, in whatever way it be treated. In any way, even accepting the Newcomb's new contribution to the study of the particular question of precession with the praise due to it, the general question still remains open. -FR. P.

\section{The Treatment of Stamp Battery Slimes from Gold Ores.}

O. page 501 of your issue of September 23, there is given a brief abstract of a paper read by myself at the July meeting of the Chemical and Iretallurgical Society of South Africa.

The essential features of the paper have hardly been correctly rendered in the condensation, inasmuch as at present mechanical stirrers are employed for agitation of slime-pulp, jets of air serving merely for oxidation, though their use as a means of agitation is suggested.

The primary use of aeration is described in the paper as the oxidation of $\mathrm{FeS}, \mathrm{FeO}_{2}, \mathrm{II}_{2}$, and other reducers, so as to effect a preliminary preparation of pulp before adding cyanide; hence the $\mathrm{KCy}$ is not protected by the presence of $\mathrm{FeS}$, which, with other ferrous compounds, has already undergone oxidation and become converted to ferric hydrate, in which state it neither consumes cyanide nor abstracts oxygen.

The $\mathrm{CO}_{z}$ in the air blown through the pulp is neutralised by the free alkali $\left(\mathrm{CaO}_{2} \mathrm{H}_{2}\right)$ present, which thus serves to protect the KCy from decomposition. Johannesburg, November 8 .

\section{Abnormal Colours of Flowers.}

IVITII reference to your correspondent's communication in NATURE for December 2, on abnornal colours of flowers, I fancy the following note may be of interest. Towards the end of 